\title{
IMPACTO DA MENSURAÇ̃̃O A VALOR JUSTO NA CRISE FINANCEIRA MUNDIAL: IDENTIFICANDO A PERCEPÇ̃̃O DE ESPECIALISTAS EM ECONOMIA E MERCADO FINANCEIRO
}

\author{
MEASURING THE IMPACT OF FAIR VALUE IN THE GLOBAL FINANCIAL CRISIS: IDEN- \\ TIFYING THE PERCEPTION OF ECONOMIC EXPERTS AND FINANCIAL MARKET
}

\section{Resumo}

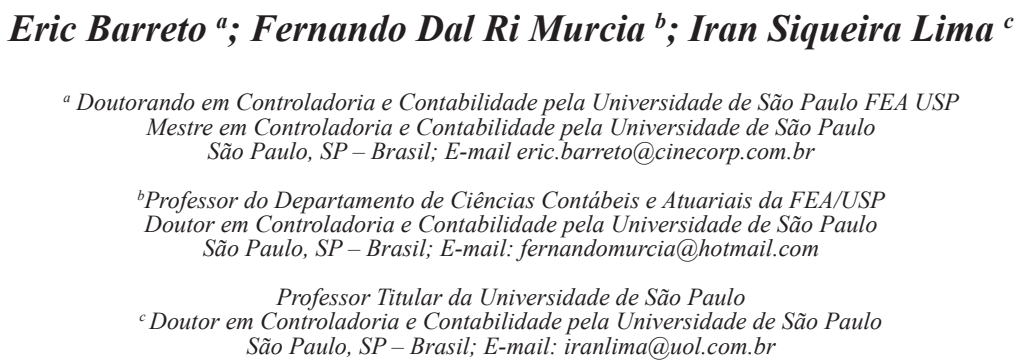

Em busca das razões que ocasionaram a crise financeira mundial, diversos aspectos relacionados à regulamentação dos mercados têm sido discutidos. Na área de contabilidade, questionase, especialmente, se a mensuração pelo valor justo (fair value), caracterizada por sua inerente subjetividade, teve algum impacto na deflagração ou no agravamento da crise financeira mundial. Dentro desse contexto, o presente estudo tem como objetivo identificar a percepção de especialistas em economia e mercado financeiro no que diz respeito ao impacto da mensuração a valor justo na crise financeira mundial. Para isso, foram realizadas entrevistas semiestruturadas com 13 profissionais com extenso conhecimento nas áreas de economia e mercados financeiros, incluindo os ex-ministros da Fazenda e os ex-presidentes do Banco Central do Brasil. Os resultados encontrados indicam que a contabilidade a valor justo não teve um papel decisivo na deflagração da crise financeira e que tampouco poderia ter evitado a mesma. Ao contrário, alguns especialistas mencionaram que a crise global talvez fosse descoberta mais tardiamente, caso os bancos não utilizassem uma contabilidade baseada no valor justo. Para os entrevistados, entre os principais fatores que ocasionaram a crise financeira, destacam-se: a alavancagem excessiva por parte dos bancos, a utilização de instrumentos financeiros modernos e a política monetária frouxa por parte do governo norte-americano.

Palavras-chave: Mensuração, valor justo, crise financeira, crise econômica..

\section{Abstract}

In the search for factors that have caused the world financial crisis, several aspects related to market regulation have been questioned by the academic community. Specifically in the accounting area, these questions regard the adoption of fair value measurements, characterized by an inherent subjectivity, opposed to historical cost approach, and its impact on the financial crises deflagration. In this scenario, the aim of this paper is to identify the perception of experts in financial market and economy regarding the impact of fair value measurement on the financial crisis. For that, semi-structured interviews with 13 professionals, including the former Ministers of Financial Affairs and the Presidents of Brazilian Central Bank, have been conducted. The results indicate that fair value accounting did not play a crucial role in the deflagration of the global financial crisis and could not have avoided it. Instead, some specialists mentioned that if fair value measurements were not used, the crisis might have been detected later. According to the experts, the main factors that triggered the crisis were: high leverage of banks, new financial instruments, and a loose monetary policy of USA government.

Keywords: Measurement, fair value, financial crisis, economic crisis. 


\section{INTRODUÇÃO}

Segundo Wolf (2009), se todas as informações estiverem disponíveis no mercado, quem não investir em sua obtenção pode beneficiar-se dos esforços onerosos de quem gastou recursos para consegui-las. Esta hipótese reduzirá os incentivos ao investimento em informações, deixando os mercados mais sujeitos aos caprichos da "ignorância racional". Se os ignorantes seguirem as pessoas que consideram mais bem informadas, ocorrerá o chamado "comportamento de manada". Finalmente, quando a incerteza é difusa e inevitável, as manadas poderão tanto inflar quanto estourar como "bolhas".

Dentro desta linha de raciocínio, seria possível dizer que, quanto maior o nível de evidenciação (disclosure) de uma companhia, menor seria a assimetria de informações. Consequentemente, o "efeito manada" seria reduzido, já que investidores com menos recursos teriam mais informações "gratuitas" (disclosure corporativo) à disposição.

Contudo, o aumento de disclosure nem sempre é desejado pelas empresas, uma vez que existem custos associados a essa demanda. Dentre eles estão os custos de propriedade que, segundo Verrecchia (2001), são os custos de divulgar informações estratégicas, cuja confidencialidade pode ser essencial para a sobrevivência da empresa.

No cenário da recente crise financeira, muitos fatores foram apontados entre os "culpados" pela criação de bolhas, e no mundo contábil, a mensuração com base no valor justo esteve entre os maiores vilões, conforme citado na Revista The Economist (2008). Os defensores do custo histórico como base de valor, argumentam que a mensuração a valor justo agravou os efeitos da crise, uma vez que a subjetividade inerente a essa mensuração teria, aparentemente, distorcido os valores reais dos eventos econômicos mensurados.

Contudo, não existe consenso sobre os fatores que efetivamente ocasionaram a crise mundial. Assumindo isto, o presente trabalho, de cunho exploratório, propõe estudar o seguinte problema de pesquisa: a contabilidade a valor justo teve impacto significativo na deflagração ou no agravamento da crise financeira mundial, segundo especialistas em economia e em mercado financeiro? Dessa forma, o artigo apresenta como objetivo: identificar a percepção de especialistas em economia e em mercado financeiro em relação ao impacto da mensuração a valor justo na crise financeira mundial.

O trabalho é desenvolvido de acordo com um método indutivo, que parte de opiniões individuais para estruturar uma opinião geral.

A presente pesquisa pretende contribuir para a evolução da regulamentação dos mercados a partir das lições aprendidas com a crise financeira. O trabalho abre o debate de um tema que, todavia, não é consenso entre profissionais e acadêmicos de varias áreas, e sua realização é justificada pelos diversos insights que contribuem para o amadurecimento dessas opiniões e pela disseminação do conhecimento que está no cerne da discussão.

Além desta breve introdução, este artigo está estruturado em quatro seções. A seção 2 trata da mensuração a valor justo e sua relação com a crise mundial, e também indica outras pesquisas sobre o tema. Na seção 3, são descritos os aspectos metodológicos para a consecução do objetivo do estudo. A seção 4 ilustra os resultados da pesquisa e a seção 5 apresenta as considerações finais do trabalho. 


\section{REFERENCIAL TEÓRICO}

\subsection{Mensuração a valor justo e a crise financeira mundial}

Pode-se dividir a contabilidade em três grandes etapas: reconhecimento, mensuração e evidenciação. Hendriksen e Van Breda (1999) definem a mensuração como "o processo de atribuição de valores monetários significativos a objetos ou eventos associados a uma empresa, e obtidos de modo a permitir agregação (tal como na avaliação total de ativos) ou desagregação, quando exigida em situações específicas”.

Um dos maiores dilemas da contabilidade, o trade-off objetividade versus relevância, tem total inserção no processo de mensuração. Obviamente, entre dois valores igualmente objetivos optar-se-á pelo mais relevante; entre dois valores igualmente relevantes, optar-se-á pelo mais objetivo. Contudo, o que fazer quando se tem um valor mais relevante e menos objetivo e outro valor menos relevante e mais objetivo? O que é preferível: o custo histórico ou o valor justo?

Para responder à pergunta é importante lembrar a definição de valor justo, que se trata de um valor subjetivo, muitas vezes não observável, diferentemente do custo histórico. O International Accounting Standards Board (IASB), em seu Exposure Draft - Fair Value Measurements (2009) define o valor justo como "o valor que seria recebido ao vender um ativo ou pago ao transferir um passivo em uma transação corriqueira entre participantes do mercado na data de mensuração" ${ }^{1 "}$.

É relevante ressaltar que essa definição entende o valor justo com um valor de saída, de acordo com IASB (2009). Martins (2001) lembra que o conflito entre a utilidade, a praticabilidade e a objetividade faz parte do cotidiano do gestor do sistema de informações. Segundo o mesmo autor, os valores de entrada são aqueles obtidos nos segmentos de mercado de compra da entidade e refletem a importância associada à obtenção dos recursos, enquanto os valores de saída, obtidos nos segmentos de venda, refletem a importância dada pelo mercado aos recursos de que a empresa dispõe.

No mercado norte-americano, a norma que trata do assunto é o SFAS 157-Fair Value Measurements, pronunciamento do Financial Accounting Standards Board, publicado em 2006, com aplicação obrigatória para exercícios iniciados a partir de 15 de novembro de 2007, que concentrou conceitos acerca da mensuração pelo valor justo e acrescentou novos requerimentos de divulgação.

Inspirado pela SFAS 157, o exposure draft do IASB (2009) requereu a segregação dos itens mensurados a valor justo em três níveis, de acordo com grau de objetividade da informação de entrada (Hierarquia do valor justo, Nível 1 - Entradas observáveis, como cotações; Nível 2 - Outras entradas observáveis; e Nível 3 - Entradas não observáveis).

Young (2008) relata que as grandes instituições financeiras norte-americanas aplicaram a SFAS 157 logo que foi publicada, muito antes de se tornar obrigatória. Com isso, os créditos de segunda linha, conhecidos no mercado como subprime, foram registrados pelo seu valor

$1 \quad$ Fair value is the price that would be received to sell an asset or paid to transfer a liability in an orderly transaction between market participants at the measurement date. 
justo, em um momento em que esse tipo de instrumento ainda tinha um grande mercado ativo. Pelo fato de existirem transações abundantes nesse mercado, os créditos foram avaliados sob o Nível 1 da "hierarquia fair value", ou seja, com base em cotações disponíveis em um mercado ativo. No entanto, assim que a inadimplência começou a afetar os títulos chamados de CDO (Collateralized Debt Obligations), lastreados em créditos subprime, e os investidores resolveram abandonar esse tipo de operação, o mercado ativo deixou de existir, o que obrigou as instituições a reavaliar seus ativos, desta vez sob os Níveis 2 e 3 da hierarquia. Preparar uma informação útil e, ao mesmo tempo, com a rapidez que os investidores esperavam não foi tarefa fácil para os contadores, que tiveram de adaptar modelos para avaliar as CDO.

O mercado se fechou rapidamente, o que obrigou as instituições a reavaliar seus modelos e premissas, fortalecendo a argumentação dos críticos da contabilidade a valor justo. Cada vez mais, a contabilidade mostrava ativos com valores abaixo das expectativas dos investidores, gerando uma frustração totalmente compreensível. Defensores do valor justo argumentam que a volatilidade vista na contabilidade nada mais é do que um reflexo da realidade, algo que em outros regimes contábeis só seria visto por pessoas de dentro das organizações. Evidentemente, muitos investidores não gostaram da informação recebida, representada por um valor numérico, que sugere uma precisão que não seria verdadeira naquele momento.

Nesse contexto, muitas demonstrações contábeis tiveram de ser ajustadas. Algumas porque seus modelos precisavam mesmo de ajustes, e outras porque as premissas precisavam ser atualizadas, o que alimentou o repertório dos críticos da contabilidade a valor justo. Esse fato também reforçou a preocupação com a mensuração do valor justo em mercados sem liquidez ou quando um mercado ativo deixa de existir.

Um estudo realizado pela Securities Exchange Comission (SEC), órgão regulador do mercado financeiro norte-americano em 2008, evidencia que os participantes do mercado entendem que as informações a respeito do valor justo são vitais em tempos de nervosismo no mercado. Nesse estudo, o Staff da SEC concluiu que a contabilidade não foi uma das causas primárias da falência dos bancos americanos em 2008. Para a maioria daquelas instituições, a contabilidade a valor justo foi aplicada de forma bastante limitada, principalmente no que tange aos passivos financieros e aos ativos não destinados à negociação, e as perdas decorrentes do valor justo não tiveram impacto significativo no patrimônio e no resultado desses bancos.

Em oposição ao uso do valor justo na contabilidade, Lopes de Sá (2008) aponta que "a questão não está em conservar valores históricos, mas sim em saber como atualizá-los de forma objetiva. A questão não está em volatilidade, mas sim em responsabilidade técnica e social. Se a informação contábil fica ao sabor do subjetivismo, ela tem toda a condição de lesar quem dela se utiliza".

Com opinião distinta, Lopes (2008) afirma que não existe uma discussão sobre o uso do fair value na avaliação de instrumentos financeiros, e reforça que o fair value é o único meio para a avaliação de derivativos, já que a maioria desses instrumentos não tem valor de custo significativo. Abandonar o fair value seria como retornar à década de 1980, quando esses instrumentos ainda eram off-balance.

Em suma, percebe-se que a mensuração pelo valor justo ainda não é consenso entre os acadêmicos e participantes do mercado. De modo potencialmente mais controverso, em tempos de crise, esse tipo de mensuração se mostra questionável. Nesse cenário, o presente estudo justifica-se como uma contribuição prática, à medida que busca identificar a opinião de especialistas do mercado. 


\subsection{Estudos anteriores a respeito do valor justo na contabilidade}

A pesquisa bibliográfica sobre estudos que abordaram o valor justo na contabilidade evidenciou que o tema ainda é pouco abordado por pesquisadores brasileiros. Dentre os estudos encontrados, ressalta-se o trabalho de Iudícibus e Martins (2007) que analisaram criticamente as normas contábeis sobre o valor justo e propuseram algumas melhorias, de forma a tornar tal mensuração mais objetiva.

Também foram encontrados outros trabalhos teóricos sobre o tema: Lisboa, Pigatto e Costa (2000) e Murcia et al. (2008). Esses dois trabalhos, assim como o estudo de Iudícibus e Martins (2007), se preocuparam em analisar criticamente os conceitos acerca do valor justo e as normas contábeis correlatas.

Também foram encontrados alguns estudos empíricos. Trombetta et al. (2007), por exemplo, examinaram a evidenciação do valor justo de instrumentos financeiros em uma amostra de bancos brasileiros e encontraram problemas no tocante à comparabilidade dessas informações. Já Murcia e Santos (2008), que analisaram o disclosure das operações com instrumentos financeiros derivativos em uma amostra de cem empresas brasileiras, identificaram a ausência de divulgação dos critérios utilizados para cálculo do valor justo. De acordo com esse estudo, a maioria das empresas divulga o valor justo das operações com derivativos, mas não apresenta os critérios que permitem identificar como tal valor foi determinado.

No cenário internacional, o tema valor justo vem sendo abordado de maneira mais recorrente pela comunidade acadêmica, principalmente nos estudos sobre 'value relevance'. Dentre os trabalhos realizados nessa área, merece destaque a pesquisa de Barth, et al. (2001), que discute a relevância desses estudos sobre value relevance para a normatização contábil. Tais estudos buscam verificar se a mensuração pelo valor justo é mais relevante que outros tipos de mensuração (como o custo histórico, por exemplo).

Nelson (1996) avaliou a associação entre o valor de mercado do patrimônio líquido de instituições bancárias e os valores justos divulgados sob a norma SFAS 107 (Disclosures about Fair Value of Financial Instruments). Os resultados sugerem que somente o valor justo de investimentos em ações tem um poder explanatório superior ao valor contábil. Não foram encontradas evidências de um incremento informacional quanto ao valor justo de empréstimos, depósitos, dívidas de longo prazo ou valor líquido de instrumentos financeiros que não eram registrados no balanço. (NELSON, 1996)

Em um trabalho de análise de bancos norte-americanos, Barth (1994) concluiu que os valores justos dos instrumentos financeiros são mais relevantes que os custos históricos, pois possuem maior poder explicativo, isto é, conseguem explicar de maneira mais acurada a variação nos preços das ações do que os valores históricos.

\section{ASPECTOS METODOLÓGICOS}

A presente pesquisa, de cunho exploratório-descritivo, tem como objetivo identificar a percepção de especialistas em economia e em mercado financeiro no que diz respeito ao impacto da mensuração pelo valor justo na crise financeira mundial. A descrição dos aspectos 
metodológicos deste estudo esta dividida em três partes: (i) roteiro e questionário de pesquisa, (ii) amostra do estudo e (iii) restrições e limitações do estudo.

\subsection{Roteiro de pesquisa}

As entrevistas normalmente são realizadas para a determinação de opiniões sobre os fatos estudados. No caso deste trabalho, apesar de haver um roteiro previamente estabelecido, que preserva a característica de comparabilidade, trata-se de uma entrevista semiestruturada, que possibilitou adaptações no roteiro, de acordo com os conhecimentos e interesses de cada entrevistado. $\mathrm{O}$ quadro 1 a seguir apresenta as questões utilizadas na condução das entrevistas.

\begin{tabular}{|c|c|}
\hline Questão & Resposta \\
\hline 1. Em sua opinião, como a atual crise financeira foi preparada? & $\begin{array}{l}\text { Aberta } \\
\text { Onde o respondente poderia inventariar os } \\
\text { fatores que influenciaram a crise. }\end{array}$ \\
\hline $\begin{array}{l}\text { 2. Em resumo, quais dos fatores inventariados pelos } \\
\text { pesquisadores colaboraram para deflagrar e/ou agravar a atual } \\
\text { crise financeira? }\end{array}$ & $\begin{array}{l}\qquad \text { Escala Likert: } \mathbf{0}-\mathbf{3} \\
\qquad \text { Onde, } 3 \text { representa os fatores com maior } \\
\text { relevância e } 0 \text { representa os fatores } \\
\text { irrelevantes. }\end{array}$ \\
\hline $\begin{array}{l}\text { 3. Alguns críticos da contabilidade pelo valor justo têm falado } \\
\text { que ela cria um efeito espiral, à medida que expõe o valor } \\
\text { recuperável do ativo cada vez que este valor é reduzido, criando } \\
\text { um novo patamar para as próximas negociações. Qual o seu } \\
\text { nível de concordância ou discordância com esta visão? }\end{array}$ & $\begin{array}{l}\text { Escala Likert: Grau de Concordância } \\
\text { Onde: } \\
\text { A) Concordo totalmente } \\
\text { B) Mais concordo que discordo } \\
\text { C) Mais discordo que concordo } \\
\text { D) Discordo totalmente }\end{array}$ \\
\hline $\begin{array}{l}\text { 4. A atual crise provavelmente seria descoberta mais tardiamente, } \\
\text { caso os bancos norte-americanos e europeus não utilizassem } \\
\text { uma contabilidade baseada no valor justo. Qual o seu nível de } \\
\text { concordância ou discordância em relação a esta afirmação? }\end{array}$ & $\begin{array}{l}\text { Escala Likert: Grau de Concordância } \\
\text { Onde: } \\
\text { A) Concordo totalmente } \\
\text { B) Mais concordo que discordo } \\
\text { C) Mais discordo que concordo } \\
\text { D) Discordo totalmente }\end{array}$ \\
\hline $\begin{array}{l}\text { 5. Contabilizar um ativo financeiro pelo valor justo significa } \\
\text { reconhecer nos balanços o seu valor de mercado, quando } \\
\text { existe um mercado líquido para este ativo, ou um valor } \\
\text { estimado, que pode ser baseado em transações recentes com } \\
\text { ativos semelhantes, técnicas de valuation, como modelos de } \\
\text { precificação de opções ou fluxo de caixa descontado. Você } \\
\text { acredita que a contabilidade baseada no valor justo colaborou } \\
\text { com o agravamento da crise financeira? }\end{array}$ & $\begin{array}{l}\text { Escala Likert: Grau de Concordância } \\
\text { Onde: } \\
\text { A) Concordo totalmente } \\
\text { B) Mais concordo que discordo } \\
\text { C) Mais discordo que concordo } \\
\text { D) Discordo totalmente }\end{array}$ \\
\hline $\begin{array}{l}\text { 6. Mesmo que a contabilidade não mostrasse o valor justo, as } \\
\text { tesourarias das instituições financeiras já acompanhavam e } \\
\text { calculavam o preço dos ativos financeiros que faziam parte de } \\
\text { suas carteiras. Dessa forma, você concorda ou discorda que, } \\
\text { mesmo sem o fair value accounting, o efeito dos preços sobre a } \\
\text { crise seria semelhante? }\end{array}$ & $\begin{array}{l}\text { Escala Likert: Grau de Concordância } \\
\text { Onde: } \\
\text { A) Concordo totalmente } \\
\text { B) Mais concordo que discordo } \\
\text { C) Mais discordo que concordo } \\
\text { D) Discordo totalmente }\end{array}$ \\
\hline
\end{tabular}

Quadro 1: Questões Utilizadas nas Entrevistas 
As entrevistas foram realizadas pessoalmente pelos autores do trabalho, sendo que cada uma delas foi gravada e arquivada eletronicamente, posteriormente transcrita, submetida à avaliação de cada entrevistado e, por fim, consolidada. No início de cada entrevista, buscou-se explicar aos entrevistados as ideias e motivações da pesquisa. Ressalta-se que o registro e a reprodução de tais entrevistas foram autorizados pelos entrevistados, de modo a identificar suas teses e percepções sobre a crise mundial.

Para aproveitar ao máximo o conhecimento dos especialistas, a primeira pergunta geral sobre a crise era totalmente aberta, permitindo a interação entre o entrevistado e o entrevistador. Em seguida, foi apresentado um inventário com possíveis explicações para a deflagração ou o agravamento da crise. Então, o entrevistado foi estimulado a atribuir notas de 0 à 3 , de acordo com a menor ou maior relevância do item. Por fim, foi aplicada uma série de perguntas fechadas com foco na contabilidade a valor justo. Contudo, nesses casos, também buscou-se estimular os comentários dos entrevistados, com o objetivo de enriquecer o trabalho.

\subsection{Amostra de especialistas em Economia e Mercado Financeiro}

Foram selecionados intencionalmente 13 profissionais com grande influência no mercado financeiro brasileiro para que suas opiniões auxiliassem na composição das conclusões deste trabalho. São eles:

1. Alkimar Moura, ex-diretor do Banco Central, Professor do Departamento de Economia da FGV e conselheiro da Bovespa.

2. Antônio Delfim Netto, ex-ministro da Fazenda e Professor Titular do Departamento de Economia da Universidade de São Paulo.

3. Arminio Fraga, ex-presidente do Banco Central e sócio da Gávea Investimentos.

4. Clive Botelho, tesoureiro do Banco Pine.

5. Gustavo Franco, ex-presidente do Banco Central e sócio da Rio Bravo Investimentos.

6. Gustavo Loyola, ex-presidente do Banco Central e sócio da Tendências Consultoria Integrada.

7. Hélio Nogueira da Cruz, Professor do Departamento de Economia da Universidade de São Paulo.

8. Marcos Eugênio da Silva, Professor do Departamento de Economia da Universidade de São Paulo.

9. Ilan Goldfajn, ex-diretor do Banco Central, Professor do Departamento de Economia da PUC - Rio e Economista do Itaú-Unibanco.

10. Maílson da Nóbrega, ex-ministro da Fazenda, sócio da Tendências Consultoria Integrada e conselheiro de diversas empresas. 
11. Maria Helena Santana, presidente da Comissão de Valores Mobiliários (CVM).

12. Roberto Padovani, ex-assessor do Ministério da Fazenda e economista do Banco WestLB.

13. Teresa Grossi, ex-diretora de fiscalização do Banco Central e membro Comitê de Auditoria do Itaú-Unibanco

\subsection{Restrições e limitações do estudo}

Esta é uma pesquisa cunho exploratório, ou seja, buscou-se apenas identificar a percepção de especialistas a respeito da deflagração e do agravamento da crise financeira mundial. Assim, o trabalho não tem como objetivo explicar ou testar as hipóteses levantadas na literatura. Do mesmo modo, a metodologia utilizada na pesquisa — entrevista semiestruturada -implica uma natural restrição no que tange à análise dos resultados, pois a interpretação das respostas depende fundamentalmente do pesquisador responsável pela coleta dos dados.

Taleb (2008) lembra que o aspecto mais preocupante do método indutivo é que o aprendizado ocorre de trás para frente, e sugere em sua obra que generalizações realizadas sob o método indutivo são sempre arriscadas. Finalmente, a amostra de especialistas foi selecionada de maneira intencional, isto é, não probabilística. Nesse sentido, os resultados da pesquisa representam apenas a percepção desses especialistas, não devendo ser generalizados para outras amostras.

\section{ANÁLISE DOS RESULTADOS}

Essa seção destina-se a apresentar as análises dos resultados da pesquisa. A seguir ilustram-se as respostas dos especialistas juntamente com comentários extraídos das entrevistas.

\section{Questão 1: Em sua opinião, como a atual crise financeira foi preparada?}

Como se tratava de uma questão aberta, isto é, o especialista tinha a opção de incluir os fatores que ocasionaram a crise, as respostas foram variadas. Para interpretar tais informações, optou-se em agrupar as respostas similares. $\mathrm{O}$ quadro 2 , no qual cada coluna representa um especialista e cada linha representa um fator determinante da crise financeira, evidencia essas análises.

Com base no quadro 2, percebe-se que os principais fatores que ocasionaram a crise financeira, na opinião dos especialistas foram: alavancagem excessiva por parte dos bancos, utilização de instrumentos financeiros modernos, e política monetária frouxa por parte do governo norte-americano. Esses três fatores foram mencionados como determinantes da crise por oito dos treze especialistas entrevistados. 


\begin{tabular}{|l|l|l|l|l|l|l|l|l|l|l|l|l|l|l|}
\hline Principais Fatores Mencionados & $\mathbf{1}$ & $\mathbf{2}$ & $\mathbf{3}$ & $\mathbf{4}$ & $\mathbf{5}$ & $\mathbf{6}$ & $\mathbf{7}$ & $\mathbf{8}$ & $\mathbf{9}$ & $\mathbf{1 0}$ & $\mathbf{1 1}$ & $\mathbf{1 2}$ & $\mathbf{1 3}$ & $\mathbf{T}$ \\
\hline Supervisão deficiente & $\mathrm{X}$ & & & & & & & & & & & $\mathrm{X}$ & & $\mathbf{2}$ \\
\hline Fé nas previsões dos economistas & $\mathrm{X}$ & $\mathrm{X}$ & & & & & & & & & $\mathrm{X}$ & & & $\mathbf{3}$ \\
\hline Fé nos modelos de risco & $\mathrm{X}$ & & & & & & & $\mathrm{X}$ & & & & $\mathrm{X}$ & $\mathbf{3}$ \\
\hline $\begin{array}{l}\text { Excesso de pessoas brilhantes no } \\
\text { setor bancário }\end{array}$ & $\mathrm{X}$ & & & & & & & $\mathrm{X}$ & & & & & $\mathbf{2}$ \\
\hline Alavancagem excessiva & $\mathbf{X}$ & & $\mathbf{X}$ & & $\mathbf{X}$ & $\mathbf{X}$ & & $\mathbf{X}$ & $\mathbf{X}$ & & $\mathbf{X}$ & $\mathbf{X}$ & & $\mathbf{8}$ \\
\hline $\begin{array}{l}\text { Operações com setores menos } \\
\text { regulados }\end{array}$ & & $\mathrm{X}$ & & & $\mathrm{X}$ & & & & & & & & & $\mathbf{2}$ \\
\hline $\begin{array}{l}\text { Instrumentos financeiros } \\
\text { modernos }\end{array}$ & & $\mathbf{X}$ & $\mathbf{X}$ & $\mathbf{X}$ & $\mathbf{X}$ & & $\mathbf{X}$ & $\mathbf{X}$ & $\mathbf{X}$ & & & & $\mathbf{X}$ & $\mathbf{8}$ \\
\hline $\begin{array}{l}\text { Política monetária frouxa nos } \\
\text { EUA }\end{array}$ & & & $\mathbf{X}$ & $\mathbf{X}$ & $\mathbf{X}$ & $\mathbf{X}$ & & $\mathbf{X}$ & $\mathbf{X}$ & $\mathbf{X}$ & & & $\mathbf{X}$ & $\mathbf{8}$ \\
\hline $\begin{array}{l}\text { Afrouxamento da política de } \\
\text { crédito }\end{array}$ & & & $\mathrm{X}$ & & & & & & $\mathrm{X}$ & & & & & $\mathbf{2}$ \\
\hline $\begin{array}{l}\text { Incentivos do governo norte- } \\
\text { americano }\end{array}$ & & & $\mathrm{X}$ & & & & & & $\mathrm{X}$ & & & $\mathrm{X}$ & $\mathrm{X}$ & $\mathbf{4}$ \\
\hline Modelo de negócios do banco & & & $\mathrm{X}$ & & & & $\mathrm{X}$ & & & & & $\mathrm{X}$ & & $\mathbf{3}$ \\
\hline Agências de rating & & & $\mathrm{X}$ & & & & & $\mathrm{X}$ & & & $\mathrm{X}$ & & & $\mathbf{3}$ \\
\hline Menor aversão ao risco & & & & $\mathbf{X}$ & & & $\mathbf{X}$ & $\mathbf{X}$ & $\mathbf{X}$ & $\mathbf{X}$ & & & & $\mathbf{5}$ \\
\hline Regulação deficiente & & & & & $\mathbf{X}$ & $\mathbf{X}$ & & $\mathbf{X}$ & & $\mathbf{X}$ & & $\mathbf{X}$ & & $\mathbf{5}$ \\
\hline $\begin{array}{l}\text { Uso de instrumentos off-balance- } \\
\text { sheet }\end{array}$ & & & & & $\mathbf{X}$ & & & & $\mathbf{X}$ & & $\mathbf{X}$ & $\mathbf{X}$ & $\mathbf{X}$ & $\mathbf{5}$ \\
\hline Remuneração dos executivos & & & & & & X & & X & & & X & & $\mathbf{3}$ \\
\hline Valor justo não teve culpa na crise & & $\mathrm{X}$ & & & & & & & & & X & X & $\mathbf{3}$ \\
\hline
\end{tabular}

\section{Quadro 2: Principais Fatores Mencionados pelos Especialistas}

Fonte: Dados da pesquisa

De acordo com Gustavo Loyola, por exemplo, "para atingir metas de inflação, os Bancos Centrais Mundiais se sentiram confortáveis em manter taxas de juros baixas, não se importando com os preços dos ativos financeiros". De acordo com o ex-presidente do Banco Central, "esse ambiente de 'fartura' leva a um comportamento menos avesso ao risco pelos agentes econômicos, isto é, esses stakeholders se tornam mais otimistas. Em tempos de exuberância, só existe memória do passado recente, e não dos tempos de maior risco, o que torna os investidores mais agressivos em termos de assunção de riscos."

Por outro lado, percebe-se que a mensuração pelo valor justo não foi um fator determinante para o agravamento da crise. De acordo com Teresa Grossi, "o único componente que não teve nenhuma culpa na deflagração da crise foi a contabilidade a valor justo". Para essa especialista, outros aspectos contábeis podem ter contribuído com a crise. Mais especificamente, a existência da possibilidade de manter certos elementos fora do balanço (off the balance sheet), o que incentivava a alavancagem por parte dos bancos.

Essa mesma linha de raciocínio é corroborada pelo Professor Delfim Netto. Segundo o ex-ministro da Fazenda do Brasil na época do "milagre econômico", "o efeito de avaliar um ativo pelo valor de mercado não teve nenhum papel relevante na deflagração ou agravamento da crise. A possibilidade de fazer operações fora do balanço, isso sim, foi um problema".

Questão 2: Em resumo, quais dos fatores inventariados pelos pesquisadores colaboraram para deflagrar elou agravar a atual crise financeira?

Conforme mencionado na descrição dos aspectos metodológicos deste estudo, a 
relevância dos fatores inventariados pelos pesquisadores foi identificada a partir de uma escala Likert, variando de 0 a 3, onde 0 representa "nem um pouco relevante", e 3 representa "muito relevante". Para facilitar a interpretação, os fatores foram agrupados com base nas notas atribuídas pelos respondentes. Os quadros 3, 4 e 5 apresentam esses resultados.

\begin{tabular}{|c|c|c|c|}
\hline Fatores que colaboraram com a deflagração da crise & Média & Mediana & Moda \\
\hline Incentivos e remuneração dos gestores & 2,33 & 3,00 & 3,00 \\
\hline Regulação deficiente & 2,25 & 2,50 & 3,00 \\
\hline $\begin{array}{c}\text { Excesso de Liquidez mundial } \\
\text { imobiliário }\end{array}$ & 2,25 & 2,50 & 2,00 \\
\hline $\begin{array}{c}\text { Incentivos do governo ansano do crédito } \\
\text { juros) }\end{array}$ & 2,17 & 2,00 & 2,00 \\
\hline Incentivos do FED para os participantes do mercado (Politicas de taxas de & 2,17 & 2,00 & 3,00 \\
\hline Supervisão deficiente & 2,08 & 2,00 & 1,00 \\
\hline
\end{tabular}

Quadro 3: Fatores Mais Relevantes para a Deflagração da Crise Mundial

Fonte: Dados da pesquisa

Nota-se que, para os entrevistados, o fator mais relevante para a deflagração da crise mundial são os incentivos e as remunerações concedidas aos executivos. De acordo com o exministro da Fazenda Maílson da Nóbrega, "existia um incentivo perverso decorrente da forma de remuneração dos executivos de instituições financeiras, que eram bonificados pelo lucro das instituições, independentemente do fato de essas operações se tornarem ruinosas ou não no futuro."

Outro fator importante foi a regulamentação deficiente. De acordo com Maria Helena Santana, atual presidente da Comissão de Valores Mobiliários (CVM), "o ambiente regulatório, em direção à desregulamentação, não estava preparado para prevenir ou controlar a evolução do mercado". Segundo a entrevistada, "o crescimento descontrolado dos volumes de derivativos negociados no balcão, por exemplo, trouxe muito mais riscos e prejuízos do que benefícios sociais".

\begin{tabular}{|l|c|c|c|}
\hline \multicolumn{1}{|c|}{ Fatores que colaboraram com a deflagração da crise } & Média & Mediana & Moda \\
\hline Transações de bancos com setores menos regulados, como hedge funds & 1,83 & 2,00 & 3,00 \\
\hline Agências de rating não cumpriram seu papel & 1,75 & 1,50 & 1,00 \\
\hline Investidores mal informados & 1,50 & 1,50 & 0,00 \\
\hline Complexidade dos produtos financeiros modernos & 1,42 & 1,50 & 1,00 \\
\hline Globalização e liberação dos mercados & 1,42 & 1,00 & 1,00 \\
\hline Diretrizes de Basileia II para gerenciamento de riscos & 1,33 & 1,50 & 2,00 \\
\hline Deficiência dos processos de auditoria & 1,17 & 1,00 & 1,00 \\
\hline
\end{tabular}

Quadro 4: Fatores de Média Relevância para a Deflagração da Crise Mundial

Fonte: Dados da pesquisa

Com base no quadro 4, nota-se que dentre os fatores considerados relevantes para a 
deflagração da crise mundial encontram-se aspetos relacionados ao gerenciamento de riscos e à complexidade dos instrumentos financeiros modernos. De acordo com o ex-presidente do Banco Central e sócio da Gávea Investimentos, Arminio Fraga, "a administração de risco tinha se tornado, ilusoriamente, uma ciência exata, e prometia um grau de controle muito maior do que era possível na realidade".

Para esse mesmo entrevistado, "muitas entidades utilizavam sistemas de administração de risco parecidos, o que individualmente pode ter sido uma decisão racional, mas coletivamente deixava de ser. Partindo de hipóteses simplificadoras, a administração de risco conduziu as entidades ao uso generalizado de técnicas como o VaR".

\begin{tabular}{|c|c|c|c|}
\hline Fatores que colaboraram com a deflagração da crise & Média & Mediana & Moda \\
\hline Modelos de risco muito complexos & 0,92 & 1,00 & 1,00 \\
\hline Modelos de risco muito simples & 0,92 & 1,00 & 1,00 \\
\hline Regras de contabilidade do FASB ou IASB - fair value accounting & 0,67 & 0,50 & 1,00 \\
\hline
\end{tabular}

Quadro 5: Fatores Menos Relevantes para a Deflagração da Crise Mundial

Fonte: Dados da pesquisa

Com base no quadro 5, percebe-se que, na opinião dos entrevistados, as regras de mensuração pelo valor justo (fair value accounting) não representaram fator relevante na deflagração da crise mundial. Para Teresa Grossi, especialista em supervisão bancária, "a norma sobre valor justo não teve impacto". Segundo Grossi, o grande problema foram "as normas que permitiam que veículos de investimento com características particulares não fossem consolidados". Ainda de acordo com Grossi, em razão dessa brecha na norma, "algumas instituições esconderam tudo o que se passava em veículos de investimento, mostrando um grau de alavancagem menor do que existia na realidade".

Questão 3: Alguns críticos da contabilidade a valor justo têm falado que ela cria um efeito espiral, à medida que expõe o valor recuperável do ativo cada vez que este valor é reduzido, criando um novo patamar para as próximas negociações. Qual o seu nível de concordância ou discordância com esta visão?

\begin{tabular}{|c|c|}
\hline Quantidade de respondentes & Grau de concordância \\
\hline 2 & Concordo totalmente \\
\hline 8 & Mais concordo do que discordo \\
\hline 1 & Mais discordo do que concordo \\
\hline 2 & Discordo totalmente \\
\hline
\end{tabular}

Quadro 6 - Grau de Concordância com o efeito pró-cíclico da contabilidade a valor justo

Fonte: Dados da pesquisa

Percebe-se que a grande maioria dos entrevistados possui um nível de concordância alto com a afirmação de que a contabilidade a valor justo tem efeito pró-cíclico. Apesar de concordar com a afirmação, no geral, os entrevistados entendem que a informação gerada pela contabilidade a valor justo é fundamental para os investidores. De acordo com o professor 
Delfim Netto, "a avaliação a mercado é fundamental para calcular os riscos corretamente, mesmo que, tecnicamente, ainda haja muitos problemas. É um componente bastante sensível, pois é uma contabilidade onde o patrimônio flutua diariamente, e não há dúvida de que é um mecanismo muito mais útil para o investidor".

Questão 4: A atual crise provavelmente seria descoberta mais tardiamente, caso os bancos norte- americanos e europeus não utilizassem uma contabilidade baseada no valor justo. Qual o seu nível de concordância ou discordância em relação a esta afirmação?

A Crise Seria Descoberta mais Tardiamente, sem Fair Value Accounting

\begin{tabular}{|c|c|}
\hline Quantidade de respondentes & Grau de concordância \\
\hline 3 & Concordo totalmente \\
\hline 7 & Mais concordo do que discordo \\
\hline 0 & Mais discordo do que concordo \\
\hline 3 & Discordo totalmente \\
\hline
\end{tabular}

Quadro 7: Grau de Concordância com a proposição:

Fonte: Dados da pesquisa

A proposição da questão 4 foi corroborada pela maioria dos entrevistados, que entendem que a contabilidade a valor justo dá maior transparência ao processo de evidenciação, e tende a agilizar a descoberta de focos de crise, conforme ilustra o quadro 7.

Questão 5: Contabilizar um ativo financeiro pelo valor justo significa reconhecer nos balanços o seu valor de mercado, quando existe um mercado líquido para este ativo, ou um valor estimado, que pode ser baseado em transações recentes com ativos semelhantes, técnicas de valuation, como modelos de precificação de opções ou fluxo de caixa descontado. Você acredita que a contabilidade baseada no valor justo colaborou com o agravamento da crise financeira?

A Contabilidade a Valor Justo Agravou a Crise

\begin{tabular}{|c|c|}
\hline Quantidade de respondentes & Grau de concordância \\
\hline 0 & Concordo totalmente \\
\hline 6 & Mais concordo do que discordo \\
\hline 2 & Mais discordo do que concordo \\
\hline 5 & Discordo totalmente \\
\hline
\end{tabular}

Quadro 8: Grau de Concordância com a proposição:

Fonte: Dados da pesquisa

Em linha com a questão 3, o quadro 8 evidencia que quase metade dos entrevistados concorda que a contabilidade colaborou com o agravamento da crise. No entanto, dos entrevistados que concordaram com a proposição, nenhum se posicionou como "concordo totalmente", e a parte dos entrevistados que descordou da proposição, em sua grande maioria, posicionou-se no maior nível de discordância. Em termos médios, poderíamos dizer que os entrevistados mais discordam do que concordam da afirmação, porém, devido ao número reduzido da amostra, essa conclusão não pode ser assumida sem a análise dos outros resultados. 
Questão 6: Mesmo que a contabilidade não mostrasse o valor justo, as tesourarias das instituições financeiras já acompanhavam e calculavam o preço dos ativos financeiros que faziam parte das suas carteiras. Dessa forma, você concorda ou discorda que, mesmo sem o fair value accounting, o efeito dos preços sobre a crise seria semelhante?

Sem o Valor Justo o Efeito dos Preços Sobre a Crise Seria Semelhante

\begin{tabular}{|c|c|}
\hline Quantidade de respondentes & Grau de concordância \\
\hline 5 & Concordo totalmente \\
\hline 5 & Mais concordo do que discordo \\
\hline 2 & Mais discordo do que concordo \\
\hline 1 & Discordo totalmente \\
\hline
\end{tabular}

Quadro 9: Grau de Concordância com a proposição:

Fonte: Dados da pesquisa

Nota-se a tendência dos entrevistados em concordar com a proposição da questão 6. Alguns entrevistados, no entanto, colocaram ressalvas na sua resposta, informando que, sem a contabilidade a valor justo, é provável que a informação sobre os preços demorasse mais para sair das tesourarias e chegar no mercado. Nessa mesma linha de pensamento, o professor Alkimar Moura ressalta que "o fair value escancara a realidade e, mesmo que tenha um caráter pró-cíclico, favorece uma solução mais rápida”.

\section{CONSIDERAÇÕES FINAIS}

Gustavo Franco, em resposta à primeira questão desta pesquisa, afirmou que "as crises são sempre surpresa, mas após explicações, parecem evitáveis, quão boas são as explanações geradas a posteriori". Assim sendo, não é esperado que este ou outros trabalhos evitem crises em períodos subsequentes, mas que as discussões abertas aproveitem ao máximo as lições aprendidas em um mal momento da economia, e construam bases para que os erros já experimentados não se repitam.

De acordo com os especialistas em economia e em mercado financeiro entrevistados no estudo, os principais fatores que ocasionaram a crise financeira mundial foram: alavancagem excessiva por parte dos bancos, utilização de instrumentos financeiros modernos, e a política monetária frouxa por parte do governo norte-americano.

No que tange à contabilidade a valor justo, a maioria dos entrevistados acredita que:

- (i) não teve culpa alguma na deflagração da crise;

- (ii) é pró-cíclica;

- (iii) é relevante para os investidores; 
- (iv) permitiu a identificação menos tardia do cenário de crise, uma vez que trouxe maior transparência e;

- (v) caso não tivesse sido utilizada, o efeito da crise sobre os preços seria o mesmo. Nesse sentido, pode-se concluir que a percepção dos entrevistados é de que a contabilidade a valor justo não deflagrou a crise financeira mundial, embora o seu caráter pró-cíclico possa ter contribuído, em algum grau, com o seu agravamento.

O presente trabalho espera contribuir com a discussão acerca da adoção do valor justo na contabilidade. Acredita-se que tais discussões sejam importantes para prover insights ao processo de regulamentação, e também para a aceitação desses conceitos por parte do mercado. Sem dúvida, o fair value accounting representa uma ruptura do paradigma do custo histórico como base de valor. Em tempos de crise, é natural que a subjetividade citada como característica do valor justo seja atacada. Entretanto, de acordo com os resultados desta pesquisa, a contabilidade a valor justo passou no seu primeiro teste.

\section{REFERÊNCIAS}

BARTH, Mary. Fair value accounting: Evidence from investment securities and the market valuation of banks. The Accounting Review. V.69, p. 1-25, 1994.

BARTH, Mary; BEAVER, William; LANDSMAN, Wayne. The Relevance of Value Relevance Literature for Financial Accounting Standard Setting: Another View. Journal of Accounting and Economics. V.31, p.77-104, 2001.

HENDRIKSEN, E. \& VAN BREDA, M. F. Teoria da Contabilidade. 8a ed. São Paulo: Atlas, 1999.

INTERNATIONAL ACCOUNTING STANDARDS BOARD (IASB). IAS 39 - Financial Instruments. 2005.

INTERNATIONAL ACCOUNTING STANDARDS BOARD (IASB). Discussion Paper Fair Value Measurements. 2007.

INTERNATIONAL ACCOUNTING STANDARDS BOARD (IASB). Exposure Draft - Fair Value Measurements. 2009.

IUDÍCIBUS, Sérgio de; MARTINS, Eliseu. Uma investigação e uma proposição sobre o conceito e o uso do valor justo. Revista de Contabilidade e Finanças da USP, n. 44, 2007.

LISBOA, Lázaro P.; PIGATTO, José A. M.; COSTA, Fábio M. da. "Valor Justo" em Contabilidade. Anais do XVI Congresso Brasileiro de Contabilidade, 2000.

LOPES, Alexsandro Broedel. Palestra "Derivativos: contabilização e implicações das operações na crise atual”. São Paulo: Fipecafi, 14/11/2008.

LOPES DE SÁ, Antônio. Ajustes Contábeis e Valor Justo. Disponível em http://www.acionista. com.br/mercado/artigos_mercado/190908 antonio_lopes.htm. Acesso em 23/11/2008. 
MARTINS, Eliseu. Avaliação de Empresas: Da Mensuração Contábil à Econômica. São Paulo: Atlas, 2001.

MURCIA, Fernando; SANTOS, Ari . Regulação Contábil e a Divulgação de Informações de Operações com Instrumentos Financeiros Derivativos: Análise do Impacto da CVM N ${ }^{\circ}$ 566/08 e da CVM N 475/08 no Disclosure das Companhias Abertas no Brasil. Revista de Contabilidade e Organizações, v. 3, p. 3-21, 2009.

MURCIA, Fernando; SILVA, Adriana; BARRETO, Eric; CARVALHO, Luis Nelson. Conjectures Regarding the Adoption of Fair Value Measurements in Brazil. Revista Contemporânea de Contabilidade, v. 1, p. 11-28, 2008.

NELSON, Karen. Fair value accounting for commercial banks: An empirical analysis of SFAS No. 107. The Accounting Review. V. 71, p.161-183, 1996.

SECURITIES EXCHANGE COMMISSION (SEC). Report and Recommendations Pursuant to Section 133 of the Emergency Economic Stabilization Act. 2008.

SECURITIES EXCHANGE COMMISSION (SEC). Contabilidade - Justo valor e crise nos mercados. http://neopatrimonialismo.blogspot.com/search/label/Fair\%20Value. Acesso em 21/11/2008.

TALEB, Nassim. A lógica do cisne negro: $O$ impacto do altamente improvável.

THE ECONOMIST. All's fair: The crisis and fair-value accounting. Disponível em http:// www.economist.com/finance/displaystory.cfm?story_id=12274096. Acesso em: 16/11/2008.

TROMBETTA, Rosa et al. Uma Análise Qualitativa do Disclosure de Títulos e Valores Mobiliários das Instituições Financeiras Brasileiras Mensurados a Fair Value. Anais do VII Congresso Usp de Contabilidade e Controladoria. 2007.

VERRECCHIA, Robert. Essays on disclosure. Journal of Accounting and Economics, v. 22, p. $97-180,2001$.

WOLF, Martin. A reconstrução do sistema financeiro global. Rio de Janeiro: Elsevier, 2009.

YOUNG, Michael R. Fair Value Accounting and Subprime. http://www.willkie.com/files/ tbl_s29Publications \%5CFileUpload5686\%5C2566\%5CFair\%20Value $\% 20$ Accounting $\% 20$ and $\% 20$ Subprime.pdf. Acesso em 02/11/2008. 


\section{DADOS DOS AUTORES:}

\section{ERIC BARRETO}

CINECORP - Educação Corporativa

Avenida Queiroz Filho, 1700 - Térreo 7, Bloco B

05319-000 - São Paulo, SP - Brasil

\section{FERNANDO DAL RI MURCIA}

Universidade de São Paulo, Departamento de Contabilidade e Atuária, Faculdade de Economia Administração e Contabilidade.

Av. Professor Luciano Gualberto, 908 - Prédio FEA 3

Butantã

05508-900 - São Paulo, SP - Brasil

\section{IRAN SIQUEIRA LIMA}

Universidade de São Paulo, Departamento de Contabilidade e Atuária, Faculdade de Economia Administração e Contabilidade.

Av. Professor Luciano Gualberto, 908 - Prédio FEA 3

Butantã

05508-900 - São Paulo, SP - Brasil 